\title{
HispanismeS
}

Revue de la Société des Hispanistes Français

18 | 2021

Murs, barrières, obstacles dans les mondes hispaniques II

\section{Les murs dans Las paces de los reyes y judía de Toledo de Lope de Vega}

Los muros en Las paces de los reyes y judía de Toledo de Lope de Vega

The walls in Lope de Vega's Las paces de los reyes y judía de Toledo

\section{Morgane Kappès-Le Moing}

\section{OpenEdition}

Journals

Édition électronique

URL : https://journals.openedition.org/hispanismes/14245

DOI : 10.4000/hispanismes. 14245

ISSN : 2270-0765

Éditeur

Société des Hispanistes Français

\section{Référence électronique}

Morgane Kappès-Le Moing, "Les murs dans Las paces de los reyes y judía de Toledo de Lope de Vega », Hispanismes [En ligne], 18| 2021, mis en ligne le 31 décembre 2021, consulté le 30 janvier 2022. URL: http://journals.openedition.org/hispanismes/14245; DOI : https://doi.org/10.4000/hispanismes. 14245

Ce document a été généré automatiquement le 30 janvier 2022.

\section{cc) (†)}

Les contenus de cette revue sont mis à disposition selon les termes de la Licence Creative Commons Attribution - Pas d'Utilisation Commerciale - Pas de Modification 4.0 International. 


\title{
Les murs dans Las paces de los reyes y judía de Toledo de Lope de Vega
}

\author{
Los muros en Las paces de los reyes y judía de Toledo de Lope de Vega \\ The walls in Lope de Vega's Las paces de los reyes y judía de Toledo
}

\section{Morgane Kappès-Le Moing}

Lope de Vega a consacré deux ouvrages à la légende de la belle juive de Tolède : le poème épique intitulé La Jerusalén conquistada, publié en $1609^{1}$, et Las paces de los reyes y judía de Toledo, une comedia publiée dans la Séptima parte en $1617^{2}$. Avant lui, plusieurs chroniques médiévales, un espejo de príncipes ainsi qu'un romance donnent corps à cette légende ${ }^{3}$, mais c'est Lope qui donne le nom de Raquel à la maîtresse d'Alphonse VIII et sous ce nom, elle devient un véritable personnage littéraire, destiné à réapparaitre chez plusieurs auteurs du Siècle d'Or. Son histoire, à travers des œuvres nombreuses et diverses, reste vivante jusqu'à nos jours en Espagne mais aussi en France, en Allemagne, en Autriche ${ }^{4}$.

2 On peut rappeler en quelques mots les invariants de cette légende ${ }^{5}$ : pendant sept ans, à Tolède, le roi Alphonse VIII a délaissé sa famille et les affaires du royaume pour vivre avec une belle juive ; les nobles ont alors tué la maîtresse royale et un envoyé de Dieu a poussé le roi au repentir, lui annonçant qu'aucun descendant mâle ne lui survivrait. On voit déjà que la pièce de Lope développe la légende, puisque le titre donne à la reine abandonnée, avec qui le roi se réconcilie, une place capitale ${ }^{6}$. Ce n'est pas la seule originalité de la comedia de Lope, dont l'absence d'unité a souvent étonné la critique ${ }^{7}$.

Effectivement, dans le premier acte, le tout jeune Alfonso, porté par un entourage exclusivement masculin, franchit les murailles de Tolède puis celles de la forteresse de Zurita, légitimant ainsi son titre royal. Les figures paternelles qui l'entourent lui assignent une mission, la guerre sainte. À la fin de ce premier acte, Alfonso devient un roi justicier et marieur, semblant signer l'autonomie de cette jornada dont presque aucun personnage ne réapparaît par la suite ${ }^{8}$. À l'acte II, le roi devenu adulte, s'est apparemment conformé à la mission qu'on lui a attribuée; rentrant de croisade, il a pris épouse et va relancer la Reconquête ibérique quand il découvre, se baignant dans 
le Tage, la beauté nue de Raquel. Alfonso, malgré l'avertissement lancé par une ombre surnaturelle, va retrouver la belle juive. Le troisième acte s'ouvre à l'issue des sept années passées avec cette dernière. La reine Leonor demande alors aux nobles de tuer la belle juive et le roi, après l'intervention d'un ange, se réconcilie avec son épouse.

L'espace de l'acte I est saturé de murailles. Les didascalies initiales mentionnent d'ailleurs le «muro de Toledo ». En outre, les murailles de la ville semblent dédoublées grâce à celles de Zurita, une forteresse où se rejoue, pour y être décryptée, la prise inaugurale de Tolède. Les actes II et III, en revanche, sont dominés par un espace hors les murs, décloisonné, constitué par le Tage et «la huerta del rey», aussi connue comme «los palacios de Galiana» situés au bord du fleuve.

La forte présence des murailles à l'acte I définit une ville fortifiée qui exerce, tout au long de la pièce, sa force d'attraction. Nous considérerons donc les murailles, et plus généralement la ville fortifiée, comme un motif capital de la comedia, qui, en participant de son unité problématique, contribue à construire un sens que nous tenterons de définir. La curieuse structure de la pièce nous incite à y adapter notre étude qui sera donc consacrée, dans un premier temps, aux murailles de l'acte I, avant de s'intéresser ensuite à l'opposition du lieu fortifié et du lieu ouvert dont le roi, paradoxalement, semble prisonnier aux actes II et III.

\section{Acte I}

6 Avant l'ouverture du premier acte, et ainsi que les scènes d'exposition le montrent, Tolède est gouverné par Fernán Ruiz, un allié du roi du Léon, l'oncle d'Alfonso, qui a profité de la minorité de son neveu et des querelles nobiliaires pour étendre sa domination. Fernán Ruiz a fait le serment de ne pas confier la ville au jeune roi de Castille avant les quinze ans de ce dernier, sauf s'il parvient à pénétrer dans Tolède, à franchir ses murailles. On peut remarquer que Fernán met sur le même plan la ville de Tolède, son alcazar et l'enceinte fortifiée; nous y reviendrons.

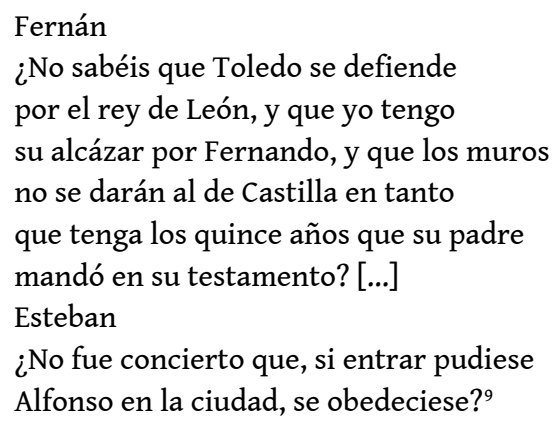

7 C'est alors qu'apparaît l'enfant-roi du haut de la tour de San Román, une église tolédane. Il a mystérieusement franchi la muraille, prenant ainsi possession de la ville, puis s'est juché sur la tour d'un bâtiment religieux qui le rapproche littéralement et symboliquement du ciel ${ }^{10}$. Les murs acquièrent donc une signification à la fois politique, en tant qu'enceinte fortifiée que l'on conquiert, et religieuse, en tant que murs d'un clocher. Ils semblent permettre la sacralisation de la personne royale et de façon générale, ils annoncent la présence du divin dans la pièce, plus explicite aux actes II et III.

8 La sacralisation du roi est d'ailleurs renforcée par les constantes évocations de sa parentèle : ses acolytes ne cessent d'évoquer son père, sa mère, son oncle, mais aucun 
de ces personnages n'est présent ; son père et sa mère sont morts, son oncle lui fait la guerre. Alfonso se choisit un père sacré, déclarant à Saint Jacques, qui lui remet miraculeusement une épée : « Nunca al Rey mi padre vi: / señor, este nombre os doy »"1.

Outre la sacralisation de la personne royale, le mur, dès les premiers vers, entoure une ville qui représente la tentation féminine de l'amour, comme le remarque d'ailleurs María Aranda, pour qui l'enjeu, au début de la pièce, est "la conquête amoureuse de Tolède $~{ }^{12}$. Manrique, l'un des deux alliés du jeune roi, clame en effet : " Toledo quiere darse a su Rey; deja / que el Rey goce a Toledo $\aleph^{13}$. C'est que le roi, malgré son tout jeune âge, n'est pas insensible aux femmes. Deux dames croisent son chemin dans ce premier acte : Elvira, l'épouse de Manrique, et Costanza, la femme de Lope de Arenas. On laisse l'enfant-roi dire à Elvira qu'elle est «[...] del mundo la otava maravilla »" mais chacune des deux figures paternelles qui entourent Alfonso le réprimande quand il apprécie le charme de Costanza. La première fois, c'est Illán qui lui lance : «Déjate de entretener / damas en esta ocasión ${ }^{15}$ » - et cette « ocasión », c'est la guerre, la prise de la forteresse de Zurita. La seconde fois, c'est Manrique qui blâme l'enfant roi : «Los soldados no han de ser / tiernos $»^{16}$. En somme, si le roi, en recevant son épée de la main de Saint Jacques, jure de défendre la foi et les dames, il doit rester insensible à leurs appâts, tel un moine soldat. Il conclut d'ailleurs lui-même : «[...] no he de ser / piadoso ni enamorado ${ }^{17}$. S'il veut faire des conquêtes, ce sont des villes qu'il doit prendre ; la seule femme qui lui soit autorisée, c'est la ville fortifiée.

10 À propos de la prise de la ville fortifiée, on se demande forcément comment le roi a pu y pénétrer sans coup férir. Au début de l'acte I, quand il apparait en haut de la tour de San Román, le mystère reste entier. Les deux personnages chargés de défendre les droits du roi du Léon sur Tolède soulignent bien le caractère incroyable de cet exploit. Lope de Arenas constate sobrement "que es imposible entrar $»^{18}$ mais Fernán, le gouverneur, se montre plus prolixe : «¿Cómo / puede ser que, guardándose las puertas / con tanta vigilancia, Alfonso entrase? $»^{19}$. Il s'exclame ensuite en voyant le roi: "¡Cielo! ¿Qué veo? » ${ }^{20}$, soulignant encore le lien entre le roi et le sacré. L'apparition royale, dans son mystère, ressemble fort à une épiphanie.

11 On ne peut s'empêcher de chercher une explication à cette énigme dans le deuxième volet du premier acte, lorsque le défi de franchir la muraille se présente de nouveau au jeune roi devant Zurita, défendue par Lope de Arenas. Ce dernier est parfaitement confiant. Ces murailles sont inexpugnables, explique-t-il à son serviteur dans une longue tirade de vingt-quatre vers que son épouse conclut ainsi : «¿No sabes tú que este fuerte / es y ha sido inexpugnable? $»^{21}$. Costanza, pourtant présentée comme un personnage d'une grande sagesse, s'enivre même d'une vaine assurance lorsqu'elle s'exclame : "Y sola, aunque soy mujer, / puedo el fuerte defender ${ }^{22}$, ajoutant enfin "Dadme un pavés y una lanza $»^{23}$, sous les encouragements de Lope de Arenas qui lui crie : «Al muro, Costanza, al muro ! $»^{24}$.

12 Pourtant, les murailles qui entourent Zurita ne protègent pas vraiment la forteresse. Il s'agit même d'une cloison tout à fait perméable, puisque plusieurs personnages la traversent sans la moindre difficulté. Il s'agit des ambassadeurs du roi, invités par Costanza, qui espère ainsi éviter la guerre. Il s'agit surtout de Dominguillo, domestique de confiance de Lope de Arenas ${ }^{25}$, qui évoque un passage, " un portillo » ${ }^{26}$, qu'il semble être le seul à connaître. Le diminutif connote le secret, donc la ruse dont va effectivement user Dominguillo. Ce dernier, se rendant auprès du roi, offre de tuer son maître contre une rente alimentaire : «Oye, señor, / si te doy el castillo / ¿dárasme que 
coma? $»^{27}$. Peu après, il poignarde Lope de Arenas et la forteresse est conquise. Les murs peuvent donc être franchis traîtreusement, grâce à la ruse.

Protection illusoire, les murs peuvent aussi fausser la perspective et faire de celui qui s'y juche le destinataire d'un spectacle qu'il ne comprend pas. C'est le cas de Lope de Arenas qui, du haut de la muraille, voit Dominguillo sortir de la forteresse pour s'approcher du monarque. Conscient d'être observé, le traitre agresse un soldat consentant et apparaît donc, aux yeux de son maître, comme un héros. Voici comment il explique son plan au roi :

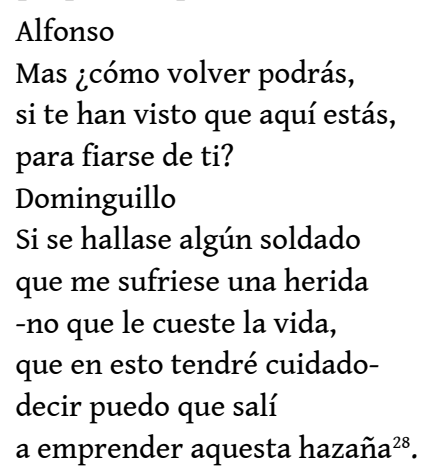

Cette petite représentation porte ses fruits puisque Lope de Arenas félicite par trois fois son serviteur en lui disant: "Notablemente anduviste ", " yo jamás / te imaginé tan valiente » et « Hombre eres de buena ley $»^{29}$. Du haut de la muraille, il semble qu'on ne surplombe pas toujours suffisamment la situation pour l'analyser avec justesse.

Il est curieux de constater qu'après la prise de Tolède, qui sacralise l'enfant roi, celle de Zurita, au contraire, semble démystifier son ascension en proposant la trahison pour toute explication, désacralisant paradoxalement la figure royale victorieuse. Un lien naît ainsi entre le roi et Dominguillo, un homme de vile naissance ${ }^{30}$, un traitre. Et le roi lui-même va renforcer ce lien puisque, récompensant la prise de la forteresse par deux mille maravédis de rente, il condamne en même temps le félon en donnant un ordre impitoyable : « sáquenle los ojos luego $»^{31}$. Comme le souligne María Aranda, la cécité de Dominguillo devient bientôt, sur un plan évidemment symbolique, celle du roi qui déclare à plusieurs reprises, aux actes II et III, qu'il est aveugle ${ }^{32}$. Si l'acte I représente l'aube d'un nouveau règne, on plonge finalement dans les ténèbres lorsque Dominguillo prononce le mot de la fin, « ...a buenas noches, señores ${ }^{33}$.

Paradoxalement, le mur est ce qui matérialise la conquête guerrière et rapproche de Dieu mais c'est aussi une protection et un promontoire illusoires. La complicité d'un traître permet de le franchir. La conquête reste pour le moins insatisfaisante, et même inachevée ${ }^{34}$. Même si le châtiment de Dominguillo relève d'une tentative de purification, quelque chose semble encore entacher la prise de Tolède, la prise du pouvoir par le jeune roi.

Sans doute est-ce parce que la ville fortifiée n'est pas le véritable enjeu de la conquête ; elle n'est que le symbole d'une victoire plus grande. La forteresse véritable qu'il s'agit de conquérir, c'est la force d'âme. D'ailleurs, en espagnol, « fortaleza » désigne à la fois la forteresse et la force d'âme. Le roi en est tout à fait conscient. Admirant le courage du soldat qui a accepté d'être blessé par Dominguillo, il lui déclare :

¿Quiéresme, Pedro, creer?

Con nacer como nací,

hoy tengo envidia de ti:

lo que eres quisiera ser. 
Más, por tan alto interés,

quisiera la fortaleza

de esa herida en la cabeza

que la corona que ves ${ }^{35}$.

On perçoit, dès lors, que le tracé de la muraille réunit le premier acte et les suivants, offrant au jeune roi le défi d'une nouvelle conquête, la nécessité de s'éloigner de Tolède pour y entrer à nouveau en vainqueur. L'enjeu, c'est bien de « ganar tan gran victoria / como el vencerse a sí mismo $»^{36}$.

\section{Actes II \& III}

À l'acte II et III, les murs et les murailles ne sont plus omniprésents. Un nouveau lieu apparait, extra muros, avant tout défini par le Tage. De façon générale, les fleuves espagnols, toujours liés au Tage, sont avant tout évoqués, dans la pièce, comme des lieux sanglants de guerre sainte. Dès l'acte I, assignant au jeune roi sa mission, Manrique lui dit, dans un jeu de mots entre le toponyme Tajo et le substantif guerrier tajo :

La ley de Dios, Alfonso, su fe santa,

habéis de hacer que el moro tiemble della;

al Bétis, al Genil, que se levanta

a ver del Tajo la corriente bella,

habéis de dar un tajo de tal modo

que su cristal se vuelva sangre todo ${ }^{37}$.

Au début de l'acte II, le fils de Manrique, appelé Garcerán, tiendra le même genre de propos, incitant lui aussi le roi à la guerre sainte :

que los caballos que hoy beben

en las corrientes del Tajo

poniente han de beber

con sangre mora manchada ${ }^{38}$.

À l'acte III enfin, l'énergie conquérante des chrétiens, détruite par l'absence royale, a disparu, et la reine, poussant les nobles au crime, se réfère également au Tage, transformant la promesse de conquête en une menace d'anéantissement :

A este paso, castellanos,

presto del Tajo las ondas,

por dicha con sangre vuestra,

beberán sus yeguas moras ${ }^{39}$.

La récurrence du mot "sangre " fait donc du Tage un espace prémonitoire pour Raquel : à l'acte II, c'est là que se baigne la belle juive de Tolède, et l'on comprend dès lors qu'elle est condamnée à mourir dans un bain de sang ${ }^{40}$. Pourtant, si le lieu est de mauvais augure, il devient aussi, un temps, propice à l'amour. Raquel s'est dénudée pour rentrer dans l'eau qui voile son corps - dans l'eau qui révèle et cache tout à la fois. Le roi, fasciné, dit à Garcerán : « ¿No ves en los cristales, vuelta en hielo, / una ninfa del Tajo que porfía / hacer del agua a todo el cuerpo un velo? $»^{41}$ Ce voile dont Raquel se couvre entièrement nous conduit à l'imaginer debout, s'aspergeant d'eau, sans doute pour apaiser le feu de son propre désir, car, bien que le roi l'ignore, on sait, grâce à un dialogue entre Raquel et sa sœur Sibila, juste avant la scène du bain, qu'elle a vu le monarque et s'en est trouvée séduite, et même enflammée ${ }^{42}$. Raquel a vu le roi sans qu'il le sache, le roi regarde Raquel sans qu'elle en ait connaissance; Lope ne montre 
pas la rencontre mais fait naître la tension d'une rencontre future à laquelle on n'assistera jamais ${ }^{43}$.

Par ailleurs, en se plongeant dans le Tage, Raquel a craint d'être vue, telle Suzanne par les vieillards. Elle demande ainsi à sa sœur Sibila :

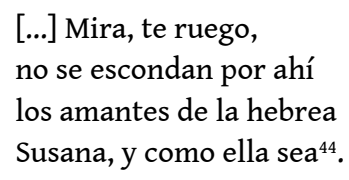

Sibila la rassure, alors que le roi, et nous-mêmes, indirectement, assistons au spectacle, en voyeurs. La scène, très belle, se caractérise par une grande tension. Se baignant dans une eau qui annonce sa mort sanglante, entre le feu et la glace, voilée mais montrée nue, observée alors qu'elle ne le souhaite pas, désirée, sans qu'elle le sache, par l'homme qu'elle désire aussi, Raquel fait du Tage un lieu éminemment érotique.

Pour le roi, en outre, l'eau est un miroir. Lorsqu'il pénètre, avec la reine, dans la ville de Tolède dont on lui offre les clés, après avoir dit toutes sortes de galanteries à son épouse, Alfonso déclare brusquement à son ami Garcerán : « Advierte / que a orillas del Tajo quiero / ir esta tarde $\aleph^{45}$. Une fois au bord de l'eau, il se confie à l'ami :

Huélgome de tratar contigo a solas, por esta orilla donde el manso viento encrespa el Tajo de corrientes olas, mi siempre recogido pensamiento. Aunque le traigo, Garcerán, conmigo, no siempre le apercibo en lo que siento. Su rostro un hombre trae siempre consigo, y no le puede ver sin un espejo; y así llaman espejo a un hombre amigo.

Mi pensamiento miro en tu consejo, que verle sin tu espejo es imposible, y por eso contigo me aconsejo ${ }^{46}$.

Souhaitant se regarder dans le miroir sincère de l'amitié, au bord du Tage, le roi découvre soudainement Raquel en train de se baigner. Désirant comprendre ses pensées profondes, il aperçoit, faisant irruption dans le miroir de la surface aquatique, ce qu'il prend pour son désir - un désir qui contraste avec la mission guerrière qu'on lui a assignée au premier acte, et que Garcerán, justement, répète encore à ce moment-là ${ }^{47}$.

C'est à cet endroit, au bord du Tage, que le roi va installer son amour, dans les palais de Galienne. Le nom renvoie à une princesse maure, qui, d'après la légende, a épousé le futur Charlemagne, se convertissant au christianisme ${ }^{48}$. Le lieu, également appelé " huerta del rey ", semble de moins mauvais augure que le Tage ; pourtant, s'il annonce effectivement une conversion in extremis de Raquel, il n'empêchera pas sa fin violente ${ }^{49}$. En effet, Garcerán déclare "que [...] ya son / más rü̈nas que palacios » avant de préciser "Tajo en todos sus espacios / ha tomado posesión " ${ }^{50}$. Le lieu de l'amour adultère avec une infidèle est celui des murs détruits qui forment avec le Tage l'espace horizontal du désir royal, s'opposant à l'espace vertical de la ville fortifiée. On a l'impression, d'une part, que le roi cherche à transformer la signification guerrière $\mathrm{du}$ fleuve en faisant du Tage le lieu de l'amour et, d'autre part, que les murs en ruines symbolisent une civilisation anéantie par l'eau de l'amour et du désir avec une force qui tient davantage d'un tsunami maritime que d'un fleuve. Le roi, d'ailleurs, dans l'unique sonnet de la pièce, compare le Tage à la mer d'Espagne ${ }^{51}$. 
Seul le père de Raquel, dont le regard est conditionné par une crainte honorable, voit des murs autour de la huerta ${ }^{52}$, comparant le palais à une forteresse dans laquelle le roi tiendrait sa fille enfermée, conformément à ce qui se passe généralement, au théâtre, dans une casa de placer, "espace d'isolement et, bien souvent, de séquestration de la femme par une instance masculine " d'après Marie-Eugénie Kaufmant ${ }^{53}$. Le frère de Raquel, quant à lui, adopte un autre point de vue :

¿Fuerte llamas lo que todos

palacios de Galïana,

puerta para todos llana

desde el tiempo de los godos? ${ }^{54}$ appréciations d'autres personnages sur ce qui se passe autour de Raquel et du roi. La reine, poussant les nobles au meurtre, provoque ainsi Garcerán : "Dime : ¿con qué te soborna? / ¿Has mezclado allá tu sangre ? ${ }^{58}$, laissant entendre qu'il entretient, lui aussi, des relations sexuelles illicites dans la huerta. Garcerán lui-même reconnaît l'existence de cette rumeur et la précise : «Y habrá alguno que diga que a su hermana / cómplice deste mal, también me inclino $\aleph^{59}$. Le palais apparaît comme un de lieu de luxure où le roi est enfermé, prisonnier d'un désir explicitement présenté comme hautement condamnable ${ }^{60}$.

33

Cortifiee conquise par l'enfant-roi, où il revient avec son épouse, la reine Leonor. Cette fois, on l'a dit, point n'est besoin de conquête ou de stratagème, on lui en offre les clés. Et la reine ne quittera plus la ville un seul instant. Au début de l'acte III, elle se trouve même à l'intérieur de la ville fortifiée, au sein de l'alcazar, dans une pièce dont elle demande que l'on ferme les portes $^{61}$. Elle rappelle ainsi l'intime imbrication, soulignée par Manrique au début de l'acte I, entre la ville, ses murs et l'alcazar, siège du pouvoir royal. Face à l'espace ouvert de la huerta, se dresse l'équivalent urbain d'un hortus conclusus, une espèce d'urbs conclusa, lieu de vertu de l'épouse légitime. La ville habitée par la reine est d'ailleurs épargnée par la colère divine qui, sous forme d'une tempête, s'abat sur la huerta :

¡Qué terrible escuridad!

¡Qué relámpagos y truenos!

Y están los cielos serenos

sobre la misma ciudad.

Sólo en la huerta parece

que el cielo muestra su furia;

debe de ser que mi injuria

siente, riñe y aborrece ${ }^{62}$. 
34 vit comme la ville fortifiée n'est plus seulement le symbole du pouvoir qu'il faut conquérir, mais aussi celui de l'amour légitime. La seule femme qui soit autorisée au roi n'est plus seulement la ville fortifiée mais aussi l'épouse aimante qui s'y trouve effectivement. Faire la guerre, aimer la femme reçue en mariage, voilà deux missions réunies au sein des murailles que le roi refuse d'abord de faire siennes, préférant la belle juive de Tolède qui, paradoxalement mais de façon significative, ne met jamais les pieds à Tolède et qui, de manière tout aussi intéressante, remet en cause, tout à la fois, l'amour conjugal et la guerre contre les infidèles.

\section{Conclusion}

Motif unificateur dont le sens se construit dans les trois actes de la comedia, le mur assigne une place au roi, une place qu'il lui faut accepter, assimiler. Quittant un espace ceint de murs, il fait l'expérience du désir désordonné pour ensuite prendre du recul et retourner parmi les siens. D'ailleurs, l'opposition entre Tolède et la huerta se résout en un troisième lieu, qui permet un dépassement de l'opposition entre la ville et la huerta, entre le lieu fermé vertical et le lieu ouvert horizontal, entre la vertu imposée et le désir subi. Après la mort de l'amante, les époux royaux se retrouvent dans le sanctuaire d'Illescas. Émergeant de la nuit tombée à la fin du premier acte, ils font, dans une aube lumineuse éclairée par Dieu ${ }^{63}$, Las paces de los reyes. C'est là qu'Alfonso accepte sa place de roi et décide de célébrer l'événement par un franchissement enfin volontaire et autonome des murailles de la ville. Il déclare - et ce sont ses derniers mots dans la pièce : "Volvámonos a Toledo, / donde mil fiestas hagamos " ${ }^{64}$. Si, accompagné de ses sujets et de sa famille, Alfonso rentre volontairement à Tolède, qui apparaît toujours comme une fortaleza, c'est qu'il ne domine pas seulement la forteresse, mais aussi la force d'âme - c'est qu'il a trouvé sa place, en tant que roi et en tant qu'homme.

\section{BIBLIOGRAPHIE}

María ARANDA, Le Galant et son double, approche théorique du théâtre de Lope de Vega dans ses figures permanentes et ses structures variables, Toulouse, Presses Universitaires du Mirail, 1995.

Lilia DAPAZ STROUT, «El proceso de individuación en Las paces de los reyes y judía de Toledo: el amor y el rol de lo femenino ", Manuel Criado de Val (dir.), Lope de Vega y los orígenes del teatro español: actas del I Congreso Internacional sobre Lope de Vega, Madrid, Edelsa, 1981, p. 485-490.

Lilia DAPAZ STROUT, « Psicomaquia o el conflicto de Eros y logos en Las paces de los reyes y judía de Toledo », Robert Fiore, Everett W. Hesse, John E. Keller, José A. Madrigal (éds.), Studies in Honour of William C. McCrary, Boulder, University of Colorado, 1986, p. 77-90.

Gustavo FAVERÓN PATRIAU, « Siete años en el Purgatorio: judíos y cristianos en Las paces de los reyes y Judía de Toledo de Lope de Vega ", Bulletin of the Comediantes, vol. 58, n 2, 2006, p. 359-382.

HispanismeS, $18 \mid 2021$ 
Marie-Eugénie KAUfMANT, Poétique des espaces naturels dans la comedia nueva, Madrid, Casa de Velázquez, 2010.

Félix LOPE DE VEGA, Jerusalén conquistada. Epopeya trágica, Antonio Carreño (éd.), Obras completas. Poesía III, Madrid, Biblioteca Castro, 2003.

Félix LOPE DE VEGA, Las paces de los reyes, James Castañeda (éd.), Chapel Hill, University of North Carolina, 1962

Félix LOPE DE VEGA, Las paces de los reyes y judía de Toledo, Enrico Di Pastena (éd.), Alberto Blecua, Guillermo Serés (dirs.), Comedias de Lope de Vega. Parte VII, Lérida, Editorial Milenio, 2008.

Roser LÓPEZ CRUZ, « 'Virgen bella, nuestras paces os encargo': Las paces de los reyes y judía de Toledo o la apuesta política por una imagen milagrosa » [on-line], Anuario de Lope de Vega. Texto, literatura, cultura, $\mathrm{n}^{\circ}$ XXXV, p. 257-280 (2019), [consulté le 22/03/2021] <URL : https://revistes.uab.cat/ anuariolopedevega/article/view/v25-lopez-cruz>.

Beatriz MARISCAL, « Historial y leyenda en el teatro de Lope de Vega, Las paces de los reyes y judía de Toledo » [on-line], Philippe Meunier, Isabelle Rouane-Soupault (dir.), Tiempo e historia en el teatro del Siglo de Oro. Actas selectas del XVI Congreso internacional (2015) [consulté le 15/02/2021] <URL : https://books.openedition.org/pup/4706>.

José Ramón MARTín LARGo, La judía de Toledo, Madrid, Brandt Editorial, 2000.

Felipe B. PEDRAZA JIMÉNEZ, La fuerza del amor y de la historia. Ensayos sobre el teatro de Lope de Vega, Madrid, Ediciones de Castilla-La Mancha, 2018.

\section{NOTES}

1. Félix LOPE DE VEGA, Jerusalén conquistada. Epopeya trágica, in Obras completas. Poesía III, Antonio Carreño (éd.), Madrid, Biblioteca Castro, 2003.

2. La date de composition reste insaisissable. Plusieurs hypothèses sont présentées dans le prologue de l'édition de Las paces de los reyes y judía de Toledo que nous utiliserons pour l'ensemble de ce travail, celle d'Enrico Di Pastena, sous la direction d'Alberto Blecua et de Guillermo Serés, incluse dans les Comedias de Lope de Vega. Parte VII, Lérida, Editorial Milenio, 2008, p. 594-703.

3. Sur la légende de la belle juive de Tolède, le travail le plus complet reste celui de James Castañeda, présenté dans l'étude préliminaire de son édition de Las paces de los reyes (Chapel Hill, University of North Carolina, 1962, p. 11-33). On peut aussi se référer à Felipe B. PEDRAZA JIMÉNEZ, La fuerza del amor y de la historia. Ensayos sobre el teatro de Lope de Vega, Madrid, Ediciones de Castilla-La Mancha, 2018 (voir, plus particulièrement, le chapitre « La judía de Toledo: génesis y cristalización de un mito literario ", p. 13-31).

4. Là encore, Castañeda propose la recherche la plus complète («Literary treatments of the legend after Lope de Vega ", Ibid., p. 63-128). On peut également consulter l'essai de José Ramón MARTín LARGo, La judía de Toledo, Madrid, Brandt Editorial, 2000. Pour ne citer que les œuvres littéraires les plus significatives reprenant le personnage de la belle juive de Tolède, on peut mentionner, au XVII ${ }^{\mathrm{e}}$ siècle, La desgraciada Raquel de Mira de Amescua; au XVIII ${ }^{\mathrm{e}}$ siècle, Raquel de García de la Huerta; au XIX ${ }^{\mathrm{e}}$ siècle, en Autriche, Die Jüdin von Toledo (La juive de Tolède) de Franz Grillparzer; au xx ${ }^{\mathrm{e}}$ siècle, en Allemagne, le roman Die Jüdin von Toledo (La juive de Tolède) de Lion Feuchtwanger et, au xxi ${ }^{\mathrm{e}}$ siècle, en Espagne, La madición de la reina Leonor de José María Pérez Peridis.

5. Las paces..., A. Castañeda (éd.), p. 11-33. 
6. Sur la présence innovante de la reine, on peut consulter l'analyse du contexte d'écriture proposée par Roser LÓPEZ CRUZ, «'Virgen bella, nuestras paces os encargo': Las paces de los reyes y judía de Toledo o la apuesta política por una imagen milagrosa » [on-line], Anuario de Lope de Vega. Texto, literatura, cultura, $\mathrm{n}^{\circ} \mathrm{XXXV}$, p. 257-280 (2019), [consulté le 22/03/2021] <URL: https:// revistes.uab.cat/anuariolopedevega/article/view/v25-lopez-cruz>.

7. Consulter à ce propos le travail de F. B. PEDRAZA JIMÉNEZ, et notamment le chapitre « La judía de Toledo y la construcción del drama moderno » (La fuerza del amor..., op. cit., p. 53-65).

8. F. B. Pedraza Jiménez considère que le premier acte semble former une «pequeña tragedia autónoma, que se cierra sobre sí misma » (Ibid., p. 24).

9. Las paces..., E. Di Pastena (éd.), vers 10-29.

10. «El comienzo de la acción en la torre es auspicioso, da una visión óptica favorable de Alfonso en las alturas e indica el principio de la búsqueda del héroe por la sabiduría » (Lilia DAPAZ STROUT, «Psicomaquia o el conflicto de Eros y logos en Las paces de los reyes y judía de Toledo ", Robert Fiore, Everett W. Hesse, John E. Keller, José A. Madrigal (éds.), Studies in Honour of William C. McCrary, Boulder, University of Colorado, 1986, p. 79).

11. Las paces..., E. Di Pastena (éd.), vers 293-294. Sur l'absence de père véritable, voir Gustavo FAVERÓN PATRIAU, «Siete años en el Purgatorio: judíos y cristianos en Las paces de los reyes y Judía de Toledo de Lope de Vega», Bulletin of the comediantes, vol. 58, $\mathrm{n}^{\circ}$ 2, 2006, p. 363.

12. María ARANDA, Le Galant et son double, approche théorique du théâtre de Lope de Vega dans ses figures permanentes et ses structures variables, Toulouse, Presses Universitaires du Mirail, 1995, p. 208.

13. Las paces..., E. Di Pastena (éd.), vers 24-25.

14. Ibid., vers 334 .

15. Ibid., vers 598-599.

16. Ibid., vers 634-635.

17. Ibid., vers 752-753. Lilia DAPAZ STROUT remarque : «El acto I presenta un estadio patriarcal y muestra el mundo duro e insensible del soldado y del rigor de la guerra en el que vivió Alfonso en su niñez " (Lilia DAPAZ STROUT, «El proceso de individuación en Las paces de los reyes y judía de Toledo : el amor y el rol de lo femenino », Manuel Criado de Val (dir.), Lope de Vega y los orígenes del teatro español: actas del I Congreso Internacional sobre Lope de Vega, Madrid, Edelsa, 1981, p. 485-490, p. 485).

18. Las paces..., E. Di Pastena (éd.), vers 31.

19. Ibid., vers 36-38.

20. Ibid., vers 40 .

21. Ibid., vers 514-515.

22. Ibid., vers 523-524.

23. Ibid., vers 526 .

24. Ibid., vers 527.

25. «De don Lope soy privanza » déclare Dominguillo au vers 236, puis de nouveau au vers 651, ce que confirme Lope de Arenas aux vers 410-411: «Es Dominguillo la llave / de cuantos secretos tengo » (Ibid.).

26. Ibid., vers 534 .

27. Ibid., vers 645-647.

28. Ibid., vers 663-671.

29. Ces trois répliques se situent respectivement aux vers 754, 764-765 et 773 (Ibid.).

30. Lope de Arenas lui-même constate, avant de rendre l'âme, que la trahison n'a pu être l'œuvre que « de un hombre mal nacido » (Ibid., vers 825).

31. Ibid., vers 903.

32. M. ARANDA Le galant..., op. cit., p. 212.

33. Ibid., vers 945 . 
34. « La toma del castillo de Zurita que se logra gracias a la traición del criado Dominguillo y no al genio militar del rey» (Beatriz MARISCAL, « Historial y leyenda en el teatro de Lope de Vega, Las paces de los reyes y judía de Toledo » [on-line], Philippe Meunier, Isabelle Rouane-Soupault (dir.), Tiempo e historia en el teatro del Siglo de Oro. Actas selectas del XVI Congreso internacional (2015) [consulté le 15/02/2021] <URL : https://books.openedition.org/pup/4706>).

35. Las paces..., E. Di Pastena (éd.), vers 710-717.

36. Ibid., vers 1476-1477.

37. Ibid., vers 255-258.

38. Ibid., vers 1019-1022.

39. Ibid., vers 2006-2009.

40. Les présages se multiplient rapidement, annonçant la fin tragique de Raquel. Ainsi, à l'acte II, le roi et la belle juive vont pêcher; chacun promet que le fruit de sa pêche sera pour l'autre. Raquel tire de l'eau un rameau d'olivier après que le roi a pêché pour elle une tête de mort (Ibid., vers 2211-2272).

41. Ibid., vers 1235-1237.

42. Raquel emploie le verbe « abrasar » (Ibid., vers 1171). Le fait que le roi perçoive la belle juive comme une nymphe de glace est surprenant car Raquel parlant avec sa sœur, ne cesse de souligner la froideur de la reine, d'origine anglaise, "nieve del norte » et " hermosa helada » (Ibid., 1126 et 1128). Elle-même se dit espagnole, donc solaire (vers 1130-1143).

43. Le galant..., op. cit., p. 215. María ARANDA parle de «deux regards incomplets, car jamais échangés. Celui des deux qui est vu ne voit pas l'autre; pis encore, le spectateur n'a jamais sous les yeux le spectacle contemplé tour à tour par les deux voyeurs. Pour le public les regards successifs portent sur un invisible objet. La non-représentation du couple est troublante dans une comedia qui relate les amours d'un homme et d'une femme ».

44. Ibid., vers 1192-1195.

45. Ibid., vers 1091-1093.

46. Ibid., vers 1201-1212.

47. Lilia DAPAZ STROUT, «El proceso de individuación... », op. cit., p. 485 : «En el acto II aparece Alfonso rebelándose en contra de los preceptos aprendidos para buscar una verdad mayor, su verdad".

48. Las paces..., E. Di Pastena (éd.), p. 694.

49. Raquel meurt après avoir prononcé ces vers : « Muero en la ley de mi Alfonso / testigos los cielos sean. / Creo en Cristo, en Cristo adoro » (Ibid., vers 2439-2441). L'adjectif possessif qu'elle utilise pour évoquer son amant souligne son amour sincère et en fait un personnage qui, malgré sa judéité, devait émouvoir les spectateurs de l'époque. L'amour de Raquel pour le roi est un trait que les dramaturges futurs, et notamment Mira de Amescua, préserveront.

50. Ibid., vers 1096-1097 et 1099-1100.

51. Ibid., vers 1290-1303.

52. Les nobles, venant assassiner Raquel, présentent, quant à eux, un lieu à peine fermé, évoquant un «cercado" qui ne suppose pas une véritable enceinte protectrice. En effet, un cercado d'après le Diccionario de Autoridades, n'est qu'un «jardín, huerto u otro lugar ceñido o cerrado con tapias $u$ otra cosa, para su resguardo». Ce lieu presque ouvert permet aussi le passage de la mort; Raquel résume bien les choses, abandonnant l'image des murs pour choisir celle de la porte : « que la más cerrada puerta / sabe la desdicha abrir » (Ibid., vers 2371-2372).

53. Marie-Eugénie KAUfMANT, Poétique des espaces naturels dans la comedia nueva, Madrid, Casa de Velázquez, 2010, p. 69. L'auteure étudie la quinta dont elle dit : «En réalité, la quinta est, le plus souvent, dans la comedia, un espace de villégiature sans fonction agricole mentionnée. Elle est alors l'équivalent de la casa de placer [...]». La huerta de Las paces de los reyes s'apparente parfaitement à cet espace caractérisé par « la tension clôture / ouverture » (Ibid., p. 141).

54. Las paces..., E. Di Pastena (éd.), vers 1705-1708.

HispanismeS, 18 | 2021 
55. Ibid., vers 1778-1779.

56. Ibid., vers 1978-198. María ARANDA déclare: «Le roi, victime d'un enchantement, devient prisonnier de son amante » (Le galant..., op. cit., p. 208).

57. Las paces..., E. Di Pastena (éd.), vers 2143.

58. Ibid., vers 2045-2046.

59. Ibid., vers $2122-2123$.

60. Garcerán utilise à plusieurs reprises l'adjectif «feo » pour qualifier l'adultère que s'apprête à commettre le roi et Belardo lui dit: «Y a vos, señor, [el cielo] os defienda / de dar en tan gran error, / porque si cristiana fuera / ya tuviérades disculpa, / mas en su ley es bajeza... / ¡Un hidalgo como vos! » (Ibid., vers 1447-1452).

61. La reine donne l'ordre suivant : «Cerrad las puertas », et l'un des nobles lui répond, insistant sur cet enfermement : « Ya están cerradas » (Ibid., vers 1940-1941).

62. Ibid., vers 1809-1816.

63. Lilia DAPAZ STROUT remarque que l'action de la pièce va « de la luz a la oscuridad y de ésta a la luz » (« Psicomaquia... », op. cit., p. 77).

64. Ibid., vers 2795-2798. María ARANDA constate également : « L'écart produit par la fuite à Illescas est dramaturgiquement pertinent car il prouve que Tolède restait à prendre (Le galant..., op. cit., p. 209).

\section{RÉSUMÉS}

Cet article définit la poétique des lieux dans Las paces de los reyes y judía de Toledo de Lope de Vega. Il interroge l'espace clos de la ville, qui symbolise la double mission attribuée au jeune roi par la génération des pères : guerre sainte et vie conjugale. Cet espace entouré de murailles s'oppose à celui du Tage et du palais de Galienne, lieux dépourvus de clôture, où le roi vit sept années durant avec la belle juive Raquel. Paradoxalement prisonnier de son propre désir dans un espace ouvert, il finira par trouver sa place grâce à un troisième lieu, permettant un dépassement dialectique de cette opposition. Il dominera ainsi la fortaleza qui, en espagnol, signifie à la fois forteresse et force d'âme.

This article defines the poetics of places in Lope de Vega's play Las paces de los reyes y judía de Toledo. It questions the enclosed space of the town, which symbolizes the twofold mission that the father's generation gave to the young king: holy war and matrimony. This place, surrounded by walls, is the opposite of the river Tagus and the palacio de Galiana, which have no fences and where the king spends seven years with Raquel, the beautiful Jewess. Paradoxically captive of his own desire in this open space, he eventually finds his place thanks to a third space, allowing him to go beyond this opposition. He thus ends up dominating the fortaleza, a word meaning both fortress and fortitude in Spanish. 
INDEX

Mots-clés : Lope de Vega, ville, murailles, espace fermé, espace ouvert, fortaleza, Las paces de los reyes y judía de Toledo

Keywords : Lope de Vega, town, wall, enclosed place, open place, fortaleza, Las paces de los reyes y judía de Toledo

\section{AUTEUR}

\section{MORGANE KAPPÈS-LE MOING}

Université Jean Monnet, St-Etienne 